\section{Unternehmen auch Baden-Württemberg erneut unter den besten Mittelständlern Deutschlands}

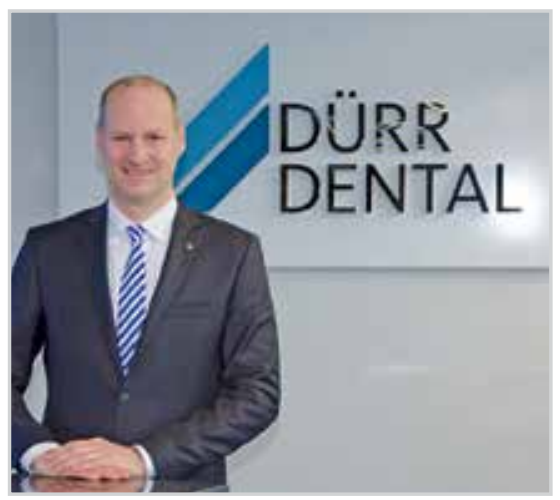

Das aktuelle Ranking des auflagenstarken Magazins WirtschaftsWoche (vom 26. Januar 2015) hat erneut die besten deutschen Mittelständler gesamtheitlich bewertet. Dabei wurden innovative und ertragsstarke Firmen des produzierenden Metallsektors aus ganz Deutschland untersucht. Bei den wachstumsstarken und technologisch führenden Firmen liegt auch 2015 die Dürr Dental AG aus Bietigheim-Bissingen (Kreis Ludwigsburg) unter den 100 besten Familienunternehmen.
„Die wiederholte Auszeichnung steht für unsere hervorragenden Mitarbeiter, die kompromisslose Qualität, die überzeugenden Produkte und eine ganz klare Konzentration auf die Herausforderungen in der anspruchsvollen Forschung für die Medizintechnik. Dies werden wir auch im März 2015 auf der weltgrößten Zahnmedizinmesse Internationale DentalSchau in Köln unter Beweis stellen“, sagt Martin Dürrstein, Vorstandsvorsitzender der Dürr Dental AG.

Nach einer Pressemitteilung der DÜRR DENTAL AG, Bietigheim-Bissingen 